\title{
Fragmentation pattern of amides by EI and HRESI: study of protonation sites using DFT-3LYP data $\uparrow$
}

Cite this: RSC Adv., 2018, 8, 21407

\author{
H. H. Fokoue, (DD a J. V. Marques, ${ }^{\text {b M. V. Correia, }}{ }^{c}$ L. F. Yamaguchi, ${ }^{d}$ X. Qu, ${ }^{e}$ J. Aires-de- \\ Sousa, ${ }^{e}$ M. T. Scotti, ${ }^{f}$ N. P. Lopes (D) and M. J. Kato ${ }^{\text {D }}{ }^{* d}$
}

Amides are important natural products which occur in a few plant families. Piplartine and piperine, major amides in Piper tuberculatum and P. nigrum, respectively, have shown a typical $\mathrm{N}-\mathrm{CO}$ cleavage when analyzed by EI-MS or HRESI-MS. In this study several synthetic analogs of piplartine and piperine were subjected to both types of mass spectrometric analysis in order to identify structural features influencing fragmentation. Most of the amides showed an intense signal of the protonated molecule $[\mathrm{M}+\mathrm{H}]^{+}$when subjected to both HRESI-MS and EI-MS conditions, with a common outcome being the cleavage of the amide bond $(\mathrm{N}-\mathrm{CO})$. This results in the loss of the neutral amine or lactam and the formation of aryl acylium cations. The mechanism of $\mathrm{N}-\mathrm{CO}$ bond cleavage persists in $\alpha, \beta$-unsaturated amides because of the stability caused by extended conjugation. Computational methods determined that the protonation of the piperamides and their derivatives takes place preferentially at the amide nitrogen supporting the dominant the $\mathrm{N}-\mathrm{CO}$ bond cleavage.

Received 20th March 2018 Accepted 4th June 2018

DOI: $10.1039 / c 7 r a 00408 g$

rsc.li/rsc-advances
Furthermore, to fully investigate their bioactivity many analogs of naturally occurring amides have been synthesized. ${ }^{\mathbf{1 0 - 1 2}}$

Our research group has focused on the phytochemistry of the genus Piper because of its wide occurrence in the tropics, ease of propagation, ecological importance and most importantly due to the previously described bioactivity of both crude extracts and isolated compounds from this genus. Thus, the development of fast and reliable tools for rapid dereplication and identification of major compounds in crude extracts became an important issue.

The application of mass spectrometry based on electron impact has already been applied to determine a series of amides in $P$. amalago. ${ }^{13}$ Two well-known amides, piperine and piplartine, have shown the cleavage of the $\mathrm{N}-\mathrm{CO}$ bond, a specific fragmentation through bioactivity-guided fractionation of crude extracts.

${ }^{a}$ Laboratório de Avaliação e Síntese de Substâncias Bioativas (LASSBio®), Instituto de Ciências Biomédicas, Centro das Ciências da Saúde, Universidade Federal do Rio de Janeiro, CP 68024, 21944-971, Rio de Janeiro, Brazil

${ }^{b}$ Ginkgo Bioworks, Boston, MA, 02210, USA

'Instituto de Química, Universidade de Brasília, CP 04478, 70704-970, Brasilia-DF, Brazil

${ }^{d}$ Instituto de Química, Universidade de São Paulo, Av. Prof. Lineu Prestes, 748, 05508o0o São Paulo-SP, Brazil. E-mail: massuojorge@gmail.com

${ }^{e} L A Q V$ and REQUIMTE, Departamento de Química, Faculdade de Ciências e Tecnologia, Universidade Nova de Lisboa, Caparica 2829-516, Portugal

${ }^{f}$ Pós-Graduação em Produtos Naturais e Sintéticos Bioativos, Universidade Federal da Paraíba, João Pessoa, 58051-900, Brazil

${ }^{g}$ Departamento de Física e Quimica, Faculdade de Ciências Farmacêuticas de Ribeirão Preto, Universidade de São Paulo, Ribeirão Preto, SP, 14040-903, Brazil

$\dagger$ Electronic supplementary information (ESI) available: EI and HRESI spectra of all compounds. See DOI: 10.1039/c7ra00408g

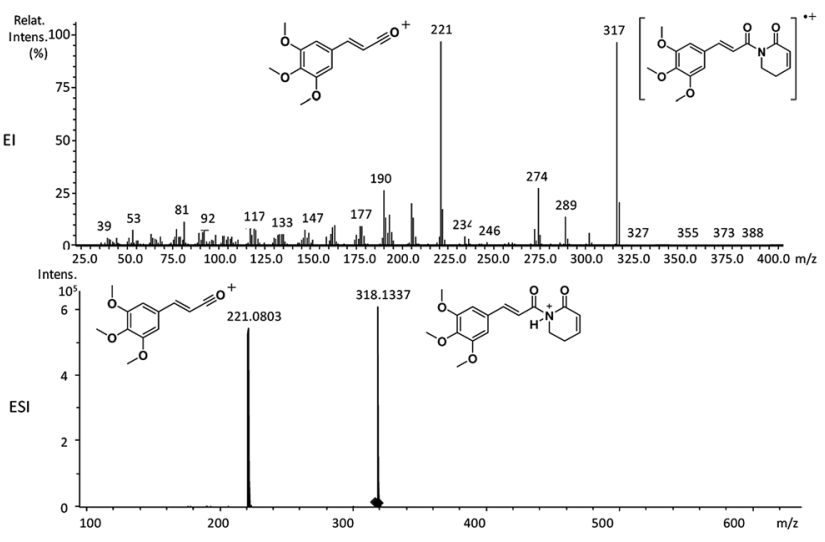

Fig. 1 EI-MS and HRESI-MS of piplartine (1a). 

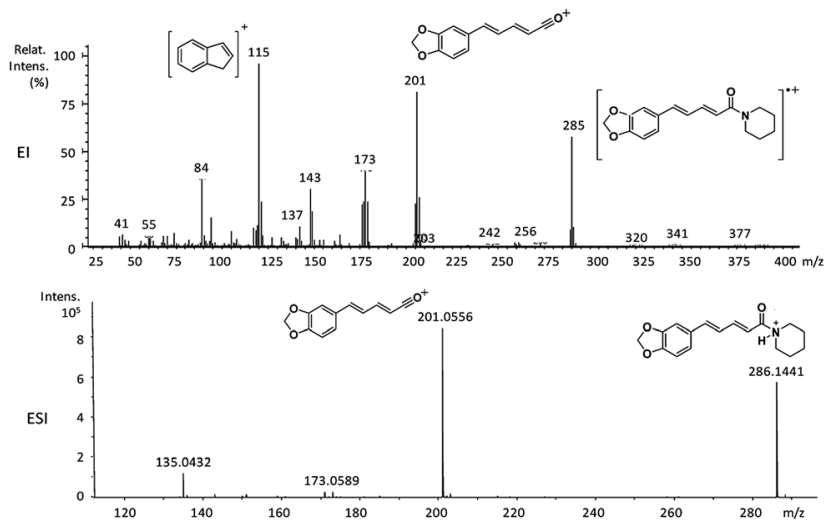

Fig. 2 EI-MS and HRESI-MS of piperine (6a).

pattern observed by EI-MS and HRESI-MS (Fig. 1 and 2). ${ }^{\mathbf{1 4 - 1 6}}$ This peculiar cleavage, observed in the $\alpha, \beta$-unsaturated piperamides is unusual in aliphatic amides, in which McLafferty rearrangement is preferable wherever $\gamma$-hydrogen to the carbonyl is available. Additionally, the $\alpha$-cleavage of secondary and tertiary aliphatic amides and the formation of acylium cations can also be used to support the characterization of amides. The conjugation between the amide carbonyl and the $\beta$ double bond reinforced by the presence of an aryl group at the $\gamma$ or 5 positions from the carbonyl could account for preferable $\mathrm{N}-\mathrm{CO}$ fragmentation. ${ }^{15,16}$ Herein, several analogs synthesized were subjected to mass spectrometry studies to determine whether the $\mathrm{N}$-CO $\alpha$-cleavage could be generalized and used as a criteria for the rapid identification of piperamides. Computational studies (proton affinity and bond energies) were carried out to verify the $\mathrm{N}-\mathrm{CO} \alpha$-cleavage. Both EI and HRESI-MS experiments were then carried out to compare the corresponding fragmentation patterns and, together a calculation of energetic profiles at protonation sites were examined to support the characterization of amides.

\section{Experimental}

\subsection{Isolation of piplartine and piperine}

Roots of Piper tuberculatum were harvested on the Campus of the University of São Paulo (USP), São Paulo, Brazil. The botanical classification was performed by Dr Elsie Franklin Guimarães (Instituto de Pesquisas Jardim Botânico do Rio de Janeiro). A voucher specimen (Kato-0169) was deposited at the Herbarium of the same institute. For the isolation of piplartine, $100 \mathrm{~g}$ of ground dry roots of $P$. tuberculatum were extracted with a mixture of chloroform/methanol $2: 1$ (1 L) for 72 hours. The solvent mixture was dried under reduced pressure using a rotoevaporator to yield a white solid which, after recrystallization in $\mathrm{MeOH},{ }^{17}$ yielded pure piplartine (1a). The identity of piplartine was confirmed by comparison of NMR and MS data with those reported. ${ }^{18,19}$

Seeds of $P$. nigrum (black-pepper) were purchased in a local market in São Paulo. Piperine (6a) was purified from $250 \mathrm{~g}$ of dried $P$. nigrum fruits. The fruits were ground to a fine powder and extracted twice with $2 \mathrm{~L}$ of chloroform/methanol $(2: 1) \mathrm{v} / \mathrm{v}$. The extract was filtered and concentrated under vacuum using a roto-evaporator. The crude extract was subjected to a silica column chromatography eluted with hexanes/ethyl acetate mixtures of increasing polarity. Fractions containing piperine (6a) were pooled and recrystallized in methanol yielding a yellowish crystal. Piperine was identified by comparison of NMR and MS analysis with reported data. ${ }^{19,20}$

\subsection{Synthesis of piplartine and piperine derivatives}

Compounds 9 and 10 were obtained by catalytic hydrogenation (4 atm of hydrogen, Pd-C) of piplartine (1a) and piperine (6a), respectively, for 12 hours. ${ }^{21}$

To a solution of 1 equivalent of carboxylic acids in dry THF (10 $\mathrm{mL}$ ) [i.e. 4-bromocinnamic acid; 5-(4-bromophenyl)-(2E,4E)-2,4pentadienoic acid; (E)-cinnamic acid; 5-(4-hydroxyphenyl)-(2E,4E)2,4-pentadienoic acid; 3,4-(methylenedioxy)-cinnamic acid or piperinic acid; (E)-3,4,5-trimethoxycinnamic acid; (E)-3,4-dimethoxycinnamic acid], kept under nitrogen atmosphere and over ice bath, oxalyl chloride (5 equiv.) was added dropwise and stirred for 6 hours. After reaching room temperature, the excess of oxalyl chloride was removed under reduced pressure to leave the corresponding acyl chlorides. Compounds 1c, 1d-1f, 2a-2d, 3a-3c, 4a,

Table 1 Structures of natural amides and derivatives ${ }^{a}$<smiles>[R]C(=O)/C=C/c1cc([R])c([R6])c([R])c1</smiles>

\begin{tabular}{|c|c|c|c|c|c|}
\hline Amides & $n$ & $\mathrm{R}_{\mathrm{a}}$ & $\mathrm{R}_{\mathrm{b}}$ & $\mathrm{R}_{\mathrm{c}}$ & $\mathrm{R}$ \\
\hline $1 a$ & 1 & OMe & OMe & $\mathrm{OMe}$ & $\mathrm{R}_{\mathrm{A}}$ \\
\hline 1b & 1 & $\mathrm{OMe}$ & OMe & $\mathrm{OMe}$ & $\mathrm{R}_{\mathrm{F}}$ \\
\hline 1c & 1 & $\mathrm{OMe}$ & OMe & $\mathrm{OMe}$ & $\mathrm{R}_{\mathrm{E}}$ \\
\hline 1d & 1 & OMe & OMe & $\mathrm{OMe}$ & $\mathrm{R}_{\mathrm{G}}$ \\
\hline $1 e$ & 1 & $\mathrm{OMe}$ & OMe & OMe & $\mathrm{R}_{\mathrm{D}}$ \\
\hline 1f & 1 & $\mathrm{OMe}$ & OMe & $\mathrm{OMe}$ & $\mathrm{R}_{\mathrm{C}}$ \\
\hline $2 a$ & 1 & $\mathrm{OMe}$ & OMe & $\mathrm{H}$ & $\mathrm{R}_{\mathrm{E}}$ \\
\hline $2 b$ & 1 & OMe & OMe & $\mathrm{H}$ & $\mathrm{R}_{\mathrm{G}}$ \\
\hline $2 c$ & 1 & $\mathrm{OMe}$ & OMe & $\mathrm{H}$ & $\mathrm{R}_{\mathrm{D}}$ \\
\hline $2 d$ & 1 & $\mathrm{OMe}$ & OMe & $\mathrm{H}$ & $\mathrm{R}_{\mathrm{C}}$ \\
\hline $2 e$ & 1 & $\mathrm{OMe}$ & OMe & $\mathrm{H}$ & $\mathrm{R}_{\mathrm{F}}$ \\
\hline $3 a$ & 1 & $\mathrm{H}$ & $\mathrm{Br}$ & $\mathrm{H}$ & $\mathrm{R}_{\mathrm{D}}$ \\
\hline $3 \mathbf{b}$ & 1 & $\mathrm{H}$ & $\mathrm{Br}$ & $\mathrm{H}$ & $\mathrm{R}_{\mathrm{G}}$ \\
\hline $3 c$ & 1 & $\mathrm{H}$ & $\mathrm{Br}$ & $\mathrm{H}$ & $\mathrm{R}_{\mathrm{E}}$ \\
\hline $4 a$ & 1 & $\mathrm{OCH}_{2} \mathrm{O}$ & & $\mathrm{H}$ & $\mathrm{R}_{\mathrm{D}}$ \\
\hline $4 b$ & 1 & $\mathrm{OCH}_{2} \mathrm{O}$ & & $\mathrm{H}$ & $\mathrm{R}_{\mathrm{E}}$ \\
\hline $5 a$ & 1 & $\mathrm{H}$ & $\mathrm{H}$ & $\mathrm{H}$ & $\mathrm{R}_{\mathrm{E}}$ \\
\hline $5 b$ & 1 & $\mathrm{H}$ & $\mathrm{H}$ & $\mathrm{H}$ & $\mathrm{R}_{\mathrm{G}}$ \\
\hline $5 c$ & 1 & $\mathrm{H}$ & $\mathrm{H}$ & $\mathrm{H}$ & $\mathrm{R}_{\mathrm{D}}$ \\
\hline $5 d$ & 1 & $\mathrm{H}$ & $\mathrm{H}$ & $\mathrm{H}$ & $\mathrm{R}_{\mathrm{F}}$ \\
\hline $6 a$ & 2 & $\mathrm{OCH}_{2} \mathrm{O}$ & & $\mathrm{H}$ & $\mathrm{R}_{\mathrm{C}}$ \\
\hline $6 b$ & 2 & $\mathrm{OCH}_{2} \mathrm{O}$ & & $\mathrm{H}$ & $\mathrm{R}_{\mathrm{G}}$ \\
\hline $7 \mathbf{a}$ & 2 & $\mathrm{H}$ & OMe & $\mathrm{H}$ & $\mathrm{R}_{\mathrm{G}}$ \\
\hline $7 \mathbf{b}$ & 2 & $\mathrm{H}$ & $\mathrm{OMe}$ & $\mathrm{H}$ & $\mathrm{R}_{\mathrm{E}}$ \\
\hline $7 c$ & 2 & $\mathrm{H}$ & OMe & $\mathrm{H}$ & $\mathrm{R}_{\mathrm{C}}$ \\
\hline $8 a$ & 2 & $\mathrm{H}$ & $\mathrm{Br}$ & $\mathrm{H}$ & $\mathrm{R}_{\mathrm{G}}$ \\
\hline $8 b$ & 2 & $\mathrm{H}$ & $\mathrm{Br}$ & $\mathrm{H}$ & $\mathrm{R}_{\mathrm{C}}$ \\
\hline 9 & $1(\Delta=0)$ & OMe & OMe & $\mathrm{OMe}$ & $\mathrm{R}_{\mathrm{B}}$ \\
\hline 10 & $2(\Delta=0)$ & $\mathrm{OCH}_{2} \mathrm{O}$ & & $\mathrm{H}$ & $\mathrm{R}_{\mathrm{C}}$ \\
\hline
\end{tabular}

${ }^{a}$ For R see Fig. 6. 
Table 2 Molecular ions $\left[\mathrm{M}^{+*}\right.$ (relative abundance\%) and significant fragmentary ions observed in El-MS spectra of amides ${ }^{a}$

\begin{tabular}{|c|c|c|c|}
\hline Amide & {$[\mathrm{M}]^{+\cdot}$} & $\mathrm{RCO}^{+}$ & Fragmentary ions \\
\hline 1a & $317(90)$ & $221(100)$ & 274 (32), 193 (20), $190(32)$ \\
\hline $1 \mathbf{b}$ & $305(100)$ & $221(55)$ & $205(40), 190(22)$ \\
\hline 1d & $307(85)$ & $221(95)$ & 236 (42), 222 (100), $191(26), 190(27), 181(55), 179(27)$ \\
\hline 1e & $307(50)$ & $221(100)$ & $222(60), 190(26)$ \\
\hline 1f & $305(60)$ & $221(65)$ & 222 (100), 194 (25), 191 (35), 190 (25), 84 (69) \\
\hline $2 \mathrm{c}$ & $277(31)$ & $191(100)$ & $192(23), 163(14)$ \\
\hline $2 d$ & $275(55)$ & $191(100)$ & $192(35), 163(20), 161(20), 84(42)$ \\
\hline $2 \mathrm{e}$ & $275(51)$ & $191(100)$ & $163(12)$ \\
\hline $3 \mathbf{a}$ & $295(21)$ & $209(72)$ & $211(70), 183(13), 181(11), 126(27), 102$ (100), 86 (52), 56 (34) \\
\hline $3 \mathbf{b}$ & $295(10)$ & $209(74)$ & $211(75), 102(100)$ \\
\hline $3 \mathbf{c}$ & $337(5)$ & $209(100)$ & $211(91), 102(100), 44(83)$ \\
\hline $5 \mathbf{c}$ & $217(18)$ & $131(100)$ & $103(60), 86(26), 77(28)$ \\
\hline $5 d$ & $215(26)$ & $131(100)$ & $187(14), 103(57), 77(32)$ \\
\hline $6 \mathbf{a}$ & $285(63)$ & $201(87)$ & $202(25), 173(42), 143(35), 115$ (100), $84(35)$ \\
\hline 6b & $287(55)$ & $201(57)$ & $173(99), 115(100)$ \\
\hline $7 \mathbf{a}$ & $273(87)$ & $187(100)$ & 188 (35), 155 (20), 159 (62), $144(60), 121(42), 115(60)$ \\
\hline $7 \mathbf{b}$ & $315(26)$ & $187(100)$ & $144(27), 128(27), 115(27), 44(35)$ \\
\hline $7 \mathrm{c}$ & $271(67)$ & $187(100)$ & $159(30), 144(40), 115(42), 84(35)$ \\
\hline $8 \mathbf{a}$ & $321(18)$ & $235(37)$ & 237 (35), $156(25), 128$ (100), $96(45)$ \\
\hline $8 \mathbf{b}$ & $319(25)$ & $235(25)$ & 237 (25), $156(27), 138(27), 129(28), 128(100), 84(74)$ \\
\hline 9 & $321(35)$ & $223(15)$ & $222(100), 194(40), 181(25), 179(55), 44(75)$ \\
\hline 10 & $289(35)$ & $205(5)$ & $204(25), 140(31), 135(25), 127$ (100), $112(52), 84(35)$ \\
\hline
\end{tabular}

$\mathbf{4 b}, \mathbf{5 a}-\mathbf{5 c}, \mathbf{6 b}, \mathbf{7 a - 7 c}, \mathbf{8 a}$ and $\mathbf{8 b}$ were synthesized by addition of triethylamine ( 3 equiv.) and the appropriate amines (i.e. $n$-dibutylamine, morpholine, $n$-pentylamine or piperidine) to a methylene chloride solution of the various acyl chlorides (1.0 equivalent). The reaction mixtures were stirred overnight at room temperature, quenched with saturated aqueous ammonium chloride solution and then extracted with methylene chloride 3 times. Combined organic phases were washed with brine and dried over anhydrous magnesium sulphate. After filtration and concentration, the residues were purified by flash chromatography over silica-gel using the hexanes-ethyl acetate (typically 10-30\%) as eluent yielding the desired amides. ${ }^{15}$

Compounds $\mathbf{1 b}, \mathbf{2 e}$ and $\mathbf{5 d}$ were synthesized by the slow addition of $n$-butyl lithium (1.3 equivalent), at $-78{ }^{\circ} \mathrm{C}$ under nitrogen atmosphere, to a solution of 2-pyrrolidinone (1.2 equiv.) in dry THF. After $15 \mathrm{~min}$, solutions of the corresponding acyl chlorides (1.0 equiv.) were added. The reaction mixtures were stirred for 1 hour at room temperature, quenched with saturated aqueous ammonium chloride solution and then extracted with ethyl acetate (3 times). Combined organic phases were washed with brine and dried over anhydrous magnesium sulphate. After filtration and concentration, the residues were purified by flash chromatography over silica-gel using the hexanes-ethyl acetate as eluent yielding the desired imides.

\subsection{Mass spectrometry instrumentation (EI-MS and HRESI-MS)}

GCMS analysis was performed using a GCMS-QP2010 Ultra gas chromatograph (Shimadzu) with an AOC-20is series injector/ autosampler (Shimadzu, Kyoto, Japan) operating in the EI mode at $70 \mathrm{eV}$ with a Rxi-5ms fused silica capillary column $(30 \mathrm{~m} \times$ $0.25 \mathrm{~mm}$ ID $\times 0.25 \mu \mathrm{m} \mathrm{df})$. The front inlet temperature was $280^{\circ} \mathrm{C}$. The helium gas flow rate through the column was $0.51 \mathrm{~mL} \mathrm{~min}{ }^{-1}$. The column temperature was held isothermally at $60{ }^{\circ} \mathrm{C}$ for $1 \mathrm{~min}$ and then ramped up from 60 to $320^{\circ} \mathrm{C}$ by $35^{\circ} \mathrm{C} \mathrm{min}{ }^{-1}$ and held isothermally for $6 \mathrm{~min}$. The transfer line and ion-source temperatures were 240 and $260{ }^{\circ} \mathrm{C}$, respectively. Experiments were recorded on scan mode over the mass range $35-500 \mathrm{~m} / \mathrm{z}$.

For HRESI-MS, the samples were analyzed by liquid chromatography and mass spectrometry Bruker MicrOTOF-QII Bruker. The High Performance Liquid Chromatograph (Shimadzu, Kyoto, Japan) was composed by two analytical pumps (model LC-20AD), an automatic injector (SIL-20AHT), a UV/Vis detector (SPD-20A), and a column oven (CTO-20A) controlled by a CBM-20A module. The mobile phase contained acetonitrile $(+0.1 \%$ of formic acid $)$ $\mathrm{v} / \mathrm{v}$ and water $(+0.1 \%$ of formic acid) $\mathrm{v} / \mathrm{v}$ and the gradient was $40 \%$ acetonitrile at $0 \mathrm{~min}$ (for up to $2 \mathrm{~min}$ ), and then it was linearly raised to $100 \%$ acetonitrile (from 2 to $30 \mathrm{~min}$ ) and kept at a plateau for $5 \mathrm{~min}$. The column was a reverse phase Luna $5 \mu \operatorname{PFP}(2) 100 \AA$, $150 \times 2 \mathrm{~mm}$ (Phenomenex). The monitored wavelength was $254 \mathrm{~nm}$, and the column oven was set at $40{ }^{\circ} \mathrm{C}$ and the mobile 
Table 3 Molecular formula, compound exact mass, HRESI $[\mathrm{M}+\mathrm{H}]^{+}$and acylium ions $\left(\mathrm{RCO}^{+}\right)$observed in $\mathrm{MS} \mathrm{MS}$ spectra of amides ${ }^{a}$

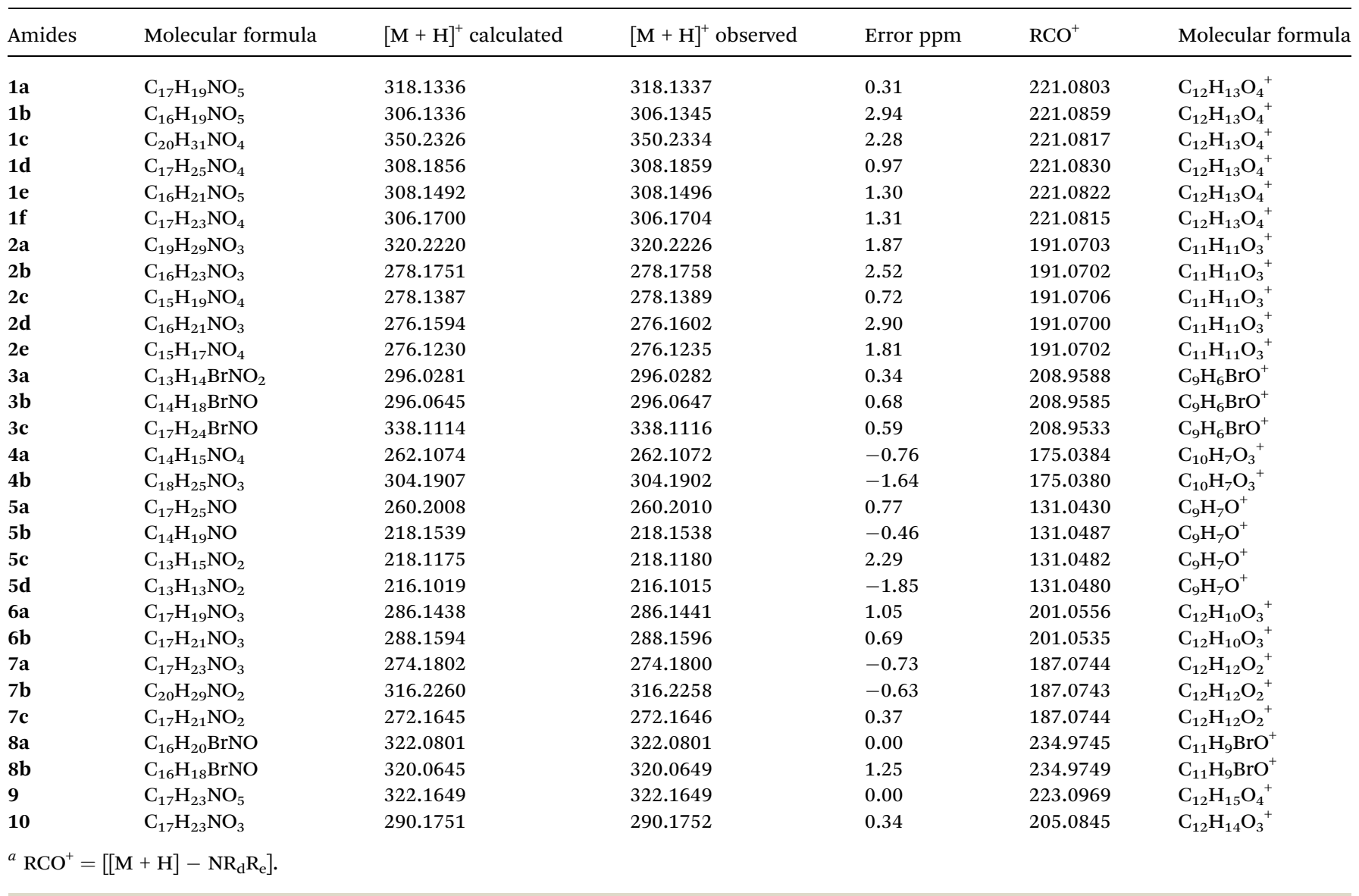

phase flow was $200 \mu \mathrm{L} \min ^{-1}$ directly infused into the mass spectrophotometer.

The mass spectrophotometer worked in positive mode with $\mathrm{N}_{2}$ as nebulizer and drying gas at $4 \mathrm{Bar}$ and $8 \mathrm{~L} \mathrm{~min}^{-1}$, respectively. The drying temperature was set to $200{ }^{\circ} \mathrm{C}$; the collision energy and the quadruple energy were set to 12 and $6 \mathrm{eV}$, respectively. RF1 and RF2 funnels were programmed to $400 \mathrm{~V}_{\mathrm{pp}}$ and the monitored mass range was 100-1000 kDa.

\subsection{NMR analysis}

${ }^{1} \mathrm{H}$ and ${ }^{13} \mathrm{C}$ NMR spectra were acquired using a Varian Gemini 200 spectrometer operating at 200 and $50 \mathrm{MHz}$, and a Bruker (DRX 300) spectrometer operating at $300 \mathrm{MHz}$ and $75 \mathrm{MHz}$, both available at the Analytical Center of the Institute of Chemistry of the University of São Paulo.

\subsection{Computational method}

Density functional theory (DFT) calculations were performed using Spartan 10 for Windows (Wavefunction Inc, Irvine, CA, USA). ${ }^{22,23}$ Each studied amide had its neutral, protonated $[\mathrm{M}+$ $\mathrm{H}]^{+}$and acyl cation forms examined at the B3LYP/6-311G* level and the lowest energy conformers were selected for the calculations. The global minimum on the potential energy surface was used for the determination of each geometry.
Proton affinity (PA) was defined as the negative of the enthalpy variation $\left(\Delta_{\mathrm{r}} H^{\circ}\right)$ for the reaction $\mathrm{M}+\mathrm{H}^{+} \rightarrow \mathrm{MH}^{+}$:

$$
\mathrm{PA}=-\Delta_{\mathrm{r}} H_{298}, \Delta_{\mathrm{r}} H_{298}=E_{\mathrm{el}}\left(\mathrm{MH}^{+}\right)-E_{\mathrm{el}}(\mathrm{M}) .
$$

For $\mathrm{H}^{+}$, no calculations are required, and the only other nonzero energy term is the difference in translational energy, which was equal to $3 / 2 R T \approx 3.7 \mathrm{~kJ} \mathrm{~mol}^{-1} \cdot{ }^{24-26}$

Additionally, bond energies were calculated using the Spartan 16 (Wavefunction Inc, Irvine, CA, USA) for windows. The energies of the compounds were calculated with DFT calculations at the level B3LYP/6-311+G** by using the single point method. ${ }^{27}$ Previously a conformational search with the molecular mechanics method MMFF (Merck Molecular Force Field) was performed and the geometry of the lowest energy conformer of each compound was optimized by using the PM6 or AM1 semi-empirical method. ${ }^{28,29}$ Bond energies between amide nitrogen and carbonyl were compared for each compound with protons bound at the amide nitrogen and at the carbonyl oxygen.

\section{Results and discussion}

The 29 amides analyzed in our study were divided in to 10 types primarily, according to the aromatic ring substitution pattern, 


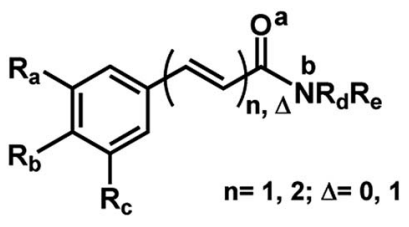

Fig. 3 General structures of amides.

Table 4 Proton affinity $\left(\mathrm{kJ} \mathrm{mol}^{-1}\right)$ of amide $(\mathrm{PA})^{a}$

\begin{tabular}{lcrr}
\hline Amides & PA(a) & PA(b) & \multicolumn{1}{c}{$\Delta P$} \\
\hline 1c & 933.66 & 903.37 & 30.29 \\
1d & 973.89 & 946.86 & 27.03 \\
1f & 984.40 & 976.82 & 7.58 \\
6a & 996.12 & 976.24 & 19.88 \\
10 & 980.89 & 945.19 & 35.70 \\
\multicolumn{2}{l}{ a and b: bonding sites for hydrogens (Fig. 3). } &
\end{tabular}

side chain size and number of double bonds varying from one double bond (1-5), two double bonds (6-8) or saturated chain (9-10) (Table 1 and Fig. 6). Piplartine (1a) and piperine (6a), the model compounds for conjugated amides, were isolated from Piper species while their derivatives were synthesized as described. Non-optimized yields of this synthesis ranged from 50 to $90 \%$ and all compounds were characterized by NMR and MS analysis (See Experimental).

Mass spectrometric analysis of amides by EI-MS quite often provides important information for their characterization. In general, aliphatic primary amides produce an intense fragmentary ion peak at $\mathrm{m} / \mathrm{z} 44\left(\mathrm{CONH}_{2}\right)$ resulting from the cleavage of the $\mathrm{R}-\mathrm{CONH}_{2}$ bond..$^{30,31}$ Aliphatic secondary and tertiary amides having hydrogens at the $\gamma$-carbon of the acyl moiety or $\mathrm{N}$-methyl groups show intense fragmentary ions resulting from McLafferty rearrangement. ${ }^{30}$ For aromatic amides a resonancestabilized benzoyl cation is formed, and this may undergo further cleavage of CO loss leading to a phenyl cation. ${ }^{31}$

Piperamides investigated in the present work have aryl groups at the position 3 (1-5) or 5 (6-10) and, are in most of the cases $\alpha, \beta$-unsaturated carbonyl amides. These peculiar

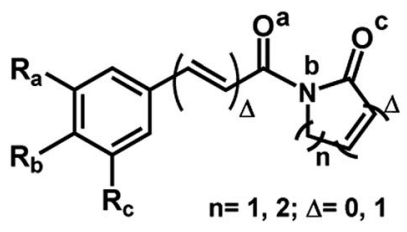

Fig. 4 General structures of imides.

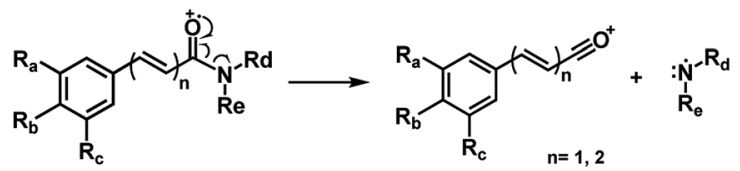

Fig. 5 Main fragmentation pattern of the amides in EI-MS.

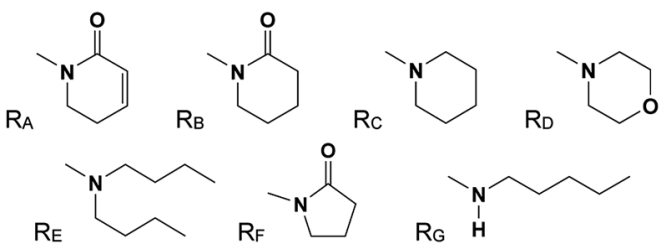

Fig. 6 Amine $\left(R_{C}, R_{D}, R_{E}, R_{G}\right)$ and lactame $\left(R_{A}, R_{B}, R_{F}\right)$ moieties.

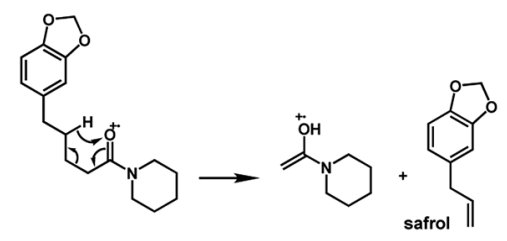

Fig. 7 McLafferty rearrangement for amide 10 under El conditions.

characteristics prevents the McLafferty rearrangement and lead frequently to the $\mathrm{N}-\mathrm{CO} \alpha$-cleavage due to conjugation of the $\alpha, \beta$ unsaturated carbonyl group of the amide (Fig. 5). For all amides analyzed under $70 \mathrm{eV}$, the relatively intense molecular ions $[\mathrm{M}]^{\cdot+}$ were observed (Table 2) and aryl acylium daughter ions were observed for all amides.

The relative intensities of the molecular ions for most of the amides were higher than $10 \%$ and quite often ranging from $50-$ $100 \%$. The only exceptions were observed to be $3 \mathbf{c}(5 \%)$ and $5 \mathbf{a}$ (7\%) and $\mathbf{5 b}(7 \%)$, which were associated to the $N, N$-dibutyl and $\mathrm{N}$-pentyl amides, respectively. The initial fragmentation yielded acylium ions which were prominent and very informative on the structures of carboxylic acid moieties in all cases. For instance, the acylium ion observed at $\mathrm{m} / \mathrm{z} 221$ for piplartine (1a), associated to the 3,4,5-trimethoxycinnamoyl ion, was also observed for 1b-1f (Table 2 and Fig. 5). Any changes in the substitution pattern of all synthetic amides were accordingly observed in the corresponding acylium ion. Thus, $m / z$ at 191 (3,4-dimethoxycinnamoyl) was observed for $2 \mathbf{a}-2 \mathbf{e} ; \mathrm{m} / \mathrm{z}$ at 209 ( $p$-bromocinnamoyl) for 3a-3c (Table 2 and Fig. 5). In the cases of amides of types $\mathbf{3}$ and $\mathbf{8}$, the typical isotope $\mathbf{M}+2$ for brominated compounds can be tracked and the acylium ion produces further the peak base at $m / z 102(100 \%)$ resulting from the loss of $\mathrm{Br}$ and $\mathrm{CO}$ (Table 2 and Fig. 5). In fact, the loss of CO from the acylium ions can be observed in most of the cases with variable intensity, excepting for $\mathbf{4 a}$ and $\mathbf{4 b}$.

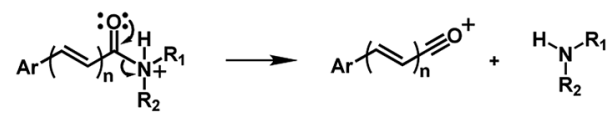

A: amides

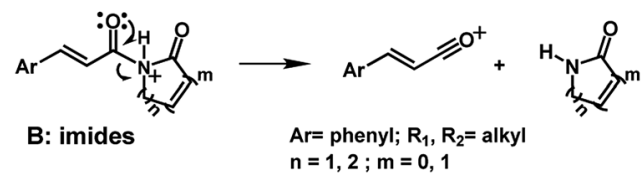

Fig. 8 Main fragmentation pathway for amides (A) and imides (B) in HRESI-MS 
Table 5 Proton affinity $\left(\mathrm{kJ} \mathrm{mol}^{-1}\right)$ of imides $(\mathrm{PA})^{a}$

\begin{tabular}{lrrr}
\hline Amide & PA(a) & PA(b) & PA(c) \\
\hline 1a & 945.75 & 898.82 & 927.77 \\
1b & 951.73 & 887.15 & 899.90 \\
2e & 981.27 & 885.84 & 899.73 \\
5d & 951.08 & 891.88 & 917.21 \\
9 & 941.94 & 889.96 & 946.81 \\
${ }^{a}$ a, b and c: bonding sites for hydrogens (Fig. 4). & \\
\hline
\end{tabular}

The amides of type $\mathbf{9}$ and $\mathbf{1 0}$ had the lowest relative abundance of the acylium ions $\mathrm{RCO}^{+}$possibly because of the lack of conjugation to the carbonyl group. In this case, the tropylium cations were observed at $m / z 181$ and 135, respectively. The tertiary amide 10, with hydrogen at the $\gamma$-carbon and not conjugated, displayed the base peak at $m / z 127$, resulting from the McLafferty rearrangement with elimination of safrole as a neutral molecule (Fig. 7).

The 10 different types of amides were further investigated under HRESI-MS conditions to determine similarities in their behavior. First, all 10 amide-types analyzed by HRESI-MS displayed intense ions of protonated molecule $[\mathrm{M}+\mathrm{H}]^{+}$(Table 3). Despite of the relative lower basicity of the amide nitrogen, the positive mode is still preferable over the negative one yielding higher intensity of ions (data not shown). As observed for the fragmentation pattern of amides using EI-MS and from previous data, ${ }^{32}$ the aryl acylium ions resulting from the $\mathrm{N}-\mathrm{CO} \alpha$-cleavage with the loss of neutral amines, were observed for all amides (Table 3) (Fig. 8). Accordingly, the formation of aryl acylium ion at $\mathrm{m} / \mathrm{z} 221$ from piplartine (1a) and at $\mathrm{m} / \mathrm{z} 201$ from piperine (6a) were observed as reported. ${ }^{\mathbf{1 4 , 1 6}}$ Indeed, the acylium ions observed in the EIMS were consistently observed in the ESIMS spectra for

Table 6 Bond energy $\left(\mathrm{kJ} \mathrm{mol}^{-1}\right)$ of amides with proton bonded at position $\mathrm{a}$ and $\mathrm{b}$ of the $\mathrm{N}-\mathrm{C}$ bond $\left(E, E_{\mathrm{a}}, E_{\mathrm{b}}\right)$ calculated with Spartan 16 software ${ }^{a}$

\begin{tabular}{lrlr}
\hline Amides & \multicolumn{1}{c}{$E_{\mathrm{a}}$} & \multicolumn{1}{c}{$E_{\mathrm{b}}$} \\
\hline 1c & 1695.86 & 211.93 & 167.08 \\
1d & 948.43 & 222.97 & 179.04 \\
1e & 890.08 & 210.00 & 180.59 \\
1f & 912.47 & 228.24 & 198.91 \\
3a & 846.79 & 125.30 & 108.94 \\
3b & 902.95 & 159.94 & 109.53 \\
3c & 1528.89 & 152.62 & 121.72 \\
4a & 801.33 & 121.38 & 99.34 \\
4b & 1490.65 & 133.37 & 101.17 \\
5a & 1522.02 & 151.48 & 100.01 \\
5b & 891.07 & 157.18 & 94.95 \\
5c & 833.14 & 147.35 & 116.79 \\
6a & 803.07 & 120.94 & 104.79 \\
6b & 838.06 & 125.59 & 96.50 \\
7a & 838.07 & 124.79 & 94.25 \\
7b & 1482.96 & 132.95 & 105.32 \\
7c & 801.67 & 129.69 & 102.17 \\
8a & 869.14 & 143.18 & 91.71 \\
8b & 822.19 & 147.12 & 108.35 \\
10 & 930.22 & 208.93 & 148.45 \\
\hline
\end{tabular}

${ }^{a}$ a and b: bonding sites for hydrogens (Fig. 3).
Table 7 Bond energy $\left(\mathrm{kJ} \mathrm{mol}^{-1}\right)$ of imides and proton bonded at a, $\mathrm{b}$ and $\mathrm{c}$ and of the $\mathrm{N}-\mathrm{C}$ bonded at position $1\left(E_{1}, E_{\mathrm{a} 1}, E_{\mathrm{b} 1}, E_{\mathrm{c} 1}\right)$ calculated by Spartan 16 software $^{a}$

\begin{tabular}{lcrrrr}
\hline position & 1a & 1b & 2e & 5d & \multicolumn{1}{c}{$\mathbf{9}$} \\
\hline$E_{1}$ & 764.92 & 774.95 & 678.95 & 731.28 & 770.14 \\
$E_{\mathrm{a} 1}$ & 148.35 & 168.29 & 86.81 & 108.23 & 99.55 \\
$E_{\mathrm{b} 1}$ & 115.22 & 97.53 & 11.76 & 38.21 & 84.98 \\
$E_{\mathrm{c} 1}$ & 139.98 & 124.70 & 39.36 & 67.22 & 112.60 \\
\multicolumn{5}{c}{ a, b and c: bonding sites for hydrogens (Fig. 4). } &
\end{tabular}

all cases (1-10) and such fragmentation is the most important for characterizing the carboxylic acid moieties. The amide $\mathbf{1 0}$ showed an aryl acylium ion at $m / z 205$ in its HRESI spectrum but also displayed ions resulting from the McLafferty rearrangement similar to what was observed with EI (Fig. 7, Tables 2 and 3).

In order to determine the preferable protonation sites for each amides in HRESI-MS, and to further elucidate the fragmentation mechanisms, the proton affinity of five amides was calculated for two main binding sites: carbonyl oxygen and amide nitrogen (a and b in Fig. 3, respectively). Five amides (1c, 1d, 1f, 6a and 10) were used as a template because their representative structures and because it was assumed that their differing substituents in the aryl group would not affect significantly the overall results. In general, compounds with proton a bonded to the nitrogen have relatively lower energy, with $\Delta P$ ranging from 7.6 to $35.7 \mathrm{~kJ} \mathrm{~mol}^{-1}$ (Table 4), supporting the formation of a protonated molecular ion with the proton preferentially bonded to the nitrogen. Thus, the elimination of the amine molecules would facilitate the formation of acylium cations.

The hydrogen bonding energy to amide nitrogen and carbonyl were calculated with Spartan software. The application of DFT at the B3LYP level, generated a set of bond energies that can be compared. The calculated bond energy values calculated by DFT-B3LYP of all the amides show that the $E_{\mathrm{b}}$ (N-C bond energy with proton attached to amide nitrogen) energies were significantly lower than the $E_{\mathrm{a}}(\mathrm{N}-\mathrm{C}$ bond energy with proton attached to the carboxyl oxygen) (Table 6) energies or not protonated amides $(E)$. Therefore, the fragmentation of the $\mathrm{N}-\mathrm{C}$ bond is preferable in order to generate the acylium ions when the proton is attached to amide nitrogen as it would be mechanistically expected.

Similar profiles of energies were observed for imide derivatives (1a, 1b, 2e, 5d and 9) (Fig. 4 and Table 5). The PA (Proton Affinity) values were lower with the hydrogens bonded to the nitrogen than to the carbonyl oxygen at position a or c (Fig. 4 and Table 5).

We also calculated the bond energies at position 1 of $\mathrm{N}-\mathrm{C}$ various of imides derivatives. The values of the bond energies calculated by DFT-B3LYP for all of the imides show that the $E_{\mathrm{b} 1}$ ( $\mathrm{N}-\mathrm{C}$ bond energy with proton attached to amide nitrogen) energies were notably lower than $E_{\mathrm{a} 1}$ and $E_{\mathrm{c} 1}$ (Table 7). Specifically, in the case of compound $\mathbf{9}$, which lacks conjugation between the carbonyl and the phenyl group, the bond energy difference is the smallest (Table 7). Thus, the fragmentation of the $\mathrm{N}-\mathrm{C}$ is similarly preferred when the proton is attached to imide nitrogen. 


\section{Conclusions}

In this work we compared the fragmentation pattern of two natural piperamides (piplartine and piperine) and several synthetic derivatives that were analysed under HRESI-MS and EI-MS conditions. Piplartine and piperine $(\alpha, \beta$-unsaturated amides) have shown a $\mathrm{N}-\mathrm{CO} \alpha$-cleavage, a characteristic fragmentation observed as a common pattern in all natural and synthetic amides. Fragmentation mechanisms were proposed based on computational analysis using DFT-B3LYP to calculate proton affinities and bond energies. The computational methods supported the fragmentation mechanism proposed in the HRESI-MS experiment involving the protonation of piperamides and derivatives preferentially in the amide nitrogen.

\section{Conflicts of interest}

There are no conflicts to declare.

\section{Acknowledgements}

The authors are grateful for financial support from the CNPq, CAPES, FAPESP (Proc. 2005/51850-9 and 2014/50316-7) and PróReitoria de Pesquisas USP. Financial support from Fundação para a Ciência e a Tecnologia (FCT/MEC) Portugal, under Project PEst-OE/QUI/UI0612/2013, and by the Associated Laboratory for Sustainable Chemistry - Clean Processes and Technologies - LAQV which is financed by national funds from FCT/ MEC (UID/QUI/50006/2013) and cofinanced by the ERDF under the PT2020 Partnership Agreement (POCI-01-0145-FEDER007265) is acknowledged.

\section{Notes and references}

1 E. M. K. Wijeratne, B. M. R. Bandara, A. A. L. Gunatilaka, Y. Tezuka and T. Kikuchi, J. Nat. Prod., 1992, 55, 1261-1269.

2 J. Sun, H.-X. Huo, J. Zhang, Z. Huang, J. Zheng, Q. Zhang, Y.-F. Zhao, J. Li and P.-F. Tu, Biochem. Syst. Ecol., 2015, 58, 265-269.

3 M. S. Ali, G. Ahmed and M. K. Pervez, J. Chem. Soc. Pak., 2012, 34, 744-747.

4 S. K. Okwute and H. O. Egharevba, Int. J. Chem., 2013, 5, 99122.

5 I. Guzman, P. W. Bosland and M. A. O'Connell, in Recent Advances in Phytochemistry 41: The Biological Activity of Phytochemicals, ed. D. R. Gang, Springer, New York, 2011.

6 L. A. Dyer, J. Richards and C. D. Dodson, in Piper. A model genus for studies of evolution, chemical ecology, and trophic interactions, ed. L. A. Dyer and A. N. Palmer, Kluwer Academic Publishers, Boston, 2004, pp. 117-139.

7 D. P. Bezerra, C. Pessoa, M. O. d. Moraes, N. M. N. d. Alencar, R. O. Mesquita, M. W. Lima, A. P. N. N. Alves, O. D. L. Pessoa, J. H. Chaves, E. R. Silveira and L. V. Costa-Lotufo, J. Appl. Toxicol., 2008, 28, 599-607.

8 D. P. Bezerra, F. O. d. Castro, A. P. N. N. Alves, C. Pessoa, M. O. d. Moraes, E. R. Silveira, M. A. S. Lima, F. J. M. Elmiro, N. M. N. d. Alencar, R. O. Mesquita,
M. W. Lima and L. V. Costa-Lotufo, J. Appl. Toxicol., 2008, 28, 156-163.

9 R. M. Gutierrez, A. M. Gonzalez and C. Hoyo-Vadillo, MiniRev. Med. Chem., 2011, 13, 163-193.

10 J. V. Marques, A. d. Oliveira, L. Raggi, M. C. M. Young and M. J. Kato, J. Braz. Chem. Soc., 2010, 21, 1807-1813.

11 R. V. da Silva, H. M. D. Navickiene, M. J. Kato, V. S. Bolzani, C. I. Meda, M. C. M. Young and M. Furlan, Phytochemistry, 2002, 59, 521-527.

12 H. M. D. Navickiene, A. C. Alécio, M. J. Kato, V. S. Bolzani, M. C. M. Young, A. J. Cavalheiro and M. Furlan, Phytochemistry, 2000, 55, 621-626.

13 H. Achenbach, W. Fietz, J. Wörth, R. Waibel and J. Portecop, Planta Med., 1986, 52, 12-18.

14 S. Bajad, M. Coumar, R. Khajuria, O. P. Suri and K. L. Bedi, Eur. J. Pharm. Sci., 2003, 19, 413-421.

15 E. A. da Silva-Junior, C. R. Paludo, D. R. Gouvea, M. J. Kato, N. A. J. C. Furtado, N. P. Lopes, R. Vessecchi and M. T. Pupo, J. Mass Spectrom., 2017, 52, 517-525.

16 E. H. Schaab, A. E. M. Crotti, Y. Iamamoto, M. J. Kato, L. V. C. Lotufo and N. P. Lopes, Biol. Pharm. Bull., 2010, 33, 912-916.

17 D. P. Bezerra, F. O. Castro, A. P. N. N. Alves, C. Pessoa, M. O. Moraes, E. R. Silveira, M. A. S. Lima, F. J. M. Elmiro and L. V. Costa-Lotufo, Braz. J. Med. Biol. Res., 2006, 39, 801-807.

18 D. Chang-Yih, W. Yang-Chang and W. Shang-Kwei, Phytochemistry, 1990, 29, 2689-2691.

19 V. S. Parmar, S. C. Jain, K. S. Bisht, R. Jain, P. Taneja, A. Jha, O. D. Tyagi, A. K. Prasad, J. Wengel, C. E. Olsen and P. M. Boll, Phytochemistry, 1997, 46, 2689-2691.

$20 \mathrm{~J}$. o. X. De Araujo-Junior, E. V. L. Da-Cunha, M. C. 1. D. O. Chaves and A. I. Gray, Phytochemistry, 1997, 44, 559-561.

21 M. Stein and B. Breit, Angew. Chem., Int. Ed., 2013, 52, 22312234.

22 A. D. Becke, Phys. Rev. A, 1988, 38, 3098-3100.

23 L. Vereecken, K. Pierloot and J. Peeters, J. Chem. Phys., 1998, 108, 1068-1080.

24 S. Mezzache, C. Pepe, P. Karoyan, F. Fournier and J. C. Tabet, Rapid Commun. Mass Spectrom., 2005, 19, 2279-2283.

25 C. Pepe, S. Rochut, J. P. Paumard and J. C. Tabet, Rapid Commun. Mass Spectrom., 2004, 18, 307-312.

26 S. Mezzache, C. Afonso, C. Pepe, P. Karoyan, F. Fournier and J. C. Tabet, Rapid Commun. Mass Spectrom., 2003, 17, 16261632.

27 J. Tirado-Rives and W. L. Jorgensen, J. Chem. Theory Comput., 2008, 4, 297-306.

28 T. A. Halgren, J. Comput. Chem., 1996, 17, 490-519.

29 J. J. P. Stewart, J. Mol. Model., 2013, 19, 1-32.

30 J. Barker, Mass spectrometry, John Wiley \& Sons Ltd, New York, 1999.

31 J. H. Gross, Mass spectrometry, a textbook, Springer, Heidelberg, 2nd edn, 2011.

32 N. Senda, H. Wakayama, T. Fujita, T. Bando, K. Shizukuishi, H. Yamaoka and M. Nakayama, J. Mass Spectrom. Soc. Jpn., 1994, 42, 325-331. 